\title{
工程建设项目招投标程序管理分析
}

\author{
熊增强 杜钰敏 \\ 西宁经济技术开发区生物科技产业园区管理委员会 \\ DOI: 10.18686/bd.v1i10.1041
}

[摘要]工程建设项目的招投标在改善工程质量、降低施工成本、提高工程收益方面都发挥着重要作用。本文对工程建设 项目招投标程序管理中存在的问题进行了论述,并讨论了相应的完善策略,希望能够为工程建设项目招投标管理提供参考。 [关键词]工程建设项目; 招投标; 程序管理

随着社会主义市场经济的发展, 各项体制已得到完善, 从而使招投标工作广泛的应用得到了各项经济活动中,尤 其是应用在工程建设领域中,招投标发挥了重要作用,已成 为工程项目建设过程中不可缺少的部分, 招投标能够有效 的降低工程建设中的成本支出, 提高工程的施工效率, 在一 定程度上也提高了施工质量。但在招投标程序管理中仍然 存在问题亟需解决,以免其影响到工程效果。

\section{1 工程建设项目招投标程序管理中存在的问题}

1.1 招投标力度不够

随着市场经济的快速发展, 我国社会各领域的监管力 度都在不断提升, 很多企业都认识到了招投标工作对企业 发展的重要作用。但在实际的经济活动中并没有真正的发 挥出招投标工作的作用, 而且也没有按照规范规定展开招 投标工作,从而导致招投标工作力度不足 ${ }^{[1]}$ 。如,在政府国有 资金项目招投标过程中, 大部分地区都采用派标的方式,而 且不是进行公开招标; 同时还存在许多未进行招投标工作 的项目, 这样不仅影响了招投标作用的发挥, 还丧失了公平 性。

\section{2 招投标操作不规范}

由于招投标在我国建筑工程领域的发展还处在初期阶 段,很多单位和个人对招投标工作都没有完整性认识,所以 实际应用和操作中存在着大量违规行为,例如虚假招标、规 避招标, 这些违规行为严重的违背了招投标工作的规范和 操作流程, 也导致后续工作难以顺利进行 ${ }^{[2]}$ 。同时, 大部分招
投标工作都缺乏管理主体, 导致很多内容无人过问, 所以导 致招投标工作经常发生混乱; 而且也会出现部分招投标项 目存在多个管理主体的现象, 这样大大的降低了工作效率, 影响了招投标工作的正常进行。

\section{3 缺乏有效的监督管理}

现阶段的招投标工作中,很多单位都会进行走后门、拉 关系等暗箱操作行为, 甚至会出现工程招标未进行但工程 已开工进行建设的问题, 严重的影响了招投标的公开、公 正、公平。归根结底出现这样的问题, 主要是由于缺乏有效 的监督管理造成的, 也导致招投标工作出现了大量的漏洞, 而且也为思想不端正的单位提供了违规违纪行为的机会。

1.4 对违规调查的力度不够

监督管理工作缺位就会导致招投标活动中出现不同类 型的徇私舞弊或不正当竞争现象, 而且目前的违规调查力 度和惩罚力度不够, 更助长了这些违规违法现象的发生。对 于违规行为的处理, 缺乏科学的处罚手段 ${ }^{[3]}$ 。所以应及时的 对相关部门和相关单位的调查制度、内容, 处罚手段、原则 进行完善, 从而及时的纠正工程单位的违规违法行为, 避免 无法追究责任现象发生。这样不仅会损失建设单位和投资 方的经济利益,还会整体招投标活动带来负面影响, 而且损 害行业的整体形象。

\section{2 完善工程建设项目招投标程序管理的策略}

2.1 规范招投标活动行为

在进行正式的招投标活动之前, 要对招标工程项目的
细的态度强化电梯制动器安装运行的质量性能要求, 必须 对制动器外观、使用性能进行综合评估, 对不确定因素要进 行反复试验, 最终确定合格后才能允许运行使用。电梯生产 部门对生产的每一步电梯制动器都要做好质量合格标记, 同时还必须承担其修理、改造和技术指导服务, 另外还必须 做好电梯制动器的技术规范调试工作, 并承担其工作职责。

\section{4 结语}

综上所述, 在电梯制动器控制检验和管理过程中, 要判 断其是否存在问题, 决不能简单从单一方面考虑, 要从综合 系统方面如断开其电气装置数量、独立性和控制运行逻辑 等诸多环节来进行研究分析, 只有这样才能精准熟练掌握
地控制电梯制动器的运行变化。一旦出现问题,才能马上提 出维修整改措施。同时,电梯设计技术监督部门和制造厂家 也要严格控制其设计制造技术层面, 这样双管齐下才能确 保电梯安全运行, 从而为人们提供更稳定安全的乘坐服务。

参考文献:

[1]宋庆福,谷其翔.电梯制动器电气控制及检验问题探 析[J]. 电子测试,2016,(18):153+116.

[2]李雨泓。电梯制动器电气控制及检验[ J]. 电子制作, 2016,(Z1):75-76.

[3] 曾相红.关于电梯制动器的电气控制分析[ J]. 科技 展望,2017,27(05):100. 
性质进行分析，以此为依据进行招投标形式和具体内容的 确定,并在招投标工作放到公开的市场环境下进行,尽最大 程度保证招投标工作的公平、公正、公开,规避单位或个人 出现的弄虚作假行为 ${ }^{[4]}$ 。同时,要实现招投标信息的高度共 享,提高招投标活动的透明度,使各单位主动接受社会各界 群体的监督。通过社会监督管理机制, 尽可能的将招投标活 动完全透明化, 减少违规行为的发生。也可以通过建立规范 的市场管理体系,杜绝地方保护主义行为,拓展招投标活动 的范围, 从而吸引更多有实力的企业加人到招投标活动中, 为工程项目建设的顺利进行奠定坚实的基础。

\section{2 规范招投标机构}

随着社会经济的快速发展, 我国很多地区都加强了基 础设施建设,随着我国工程项目建设数量提升,使得招投标 活动的应用范围越来越广, 也推动了招投标代理产业的快 速成长。招投标代理企业是指享有工程建设公司的招标或 投标代理权, 并为工程建设公司提供招投标服务的机构,也 就是工程建设公司提供材料要求代理机构按照其意愿组织 招投标活动。所以在代理机构中会出现很多不规范的行为, 政府和相关部门也要适当的制定相关法律对代理机构的行 为进行约束, 并及时的调整投标监督管理办法和方式适应 现代社会招投标活动的需要, 而且也要对代理机构的资质 进行严格的考察, 不断提高其代理水平, 从而保证招投标工 作的顺利开展 ${ }^{[5]}$ 。而且各级行政管理部门应对招投标工作中 展开的行为进行严格的规范, 制定严格的市场准人机制,并 结合目前市场经济环境下形成的信用管理办法, 对代理机 构以及相关从而人员的违法操作行为进行严厉的惩罚和制 定规范的惩罚标准,从而真正实现招投标活动的公平性、公 开性、透明性。

\section{3 规范招投标文件内容}

招投标文件是开展招投标活动的核心内容, 有着至关 重要的作用,对招投标活动的质量有着决定性的意义,所以 在整个招投标活动中不仅要对各个环节进行规范, 还要明 确活动中各利益主体需要承担的责任和义务, 对工程建设 提出相关的技术要求和操作标准等, 这些内容都会直接影 响到招投标的效果和质量。在进行工程项目招投标活动时, 要保证招投标文件的全面性和规范性, 明确体现各利益主 体的权力范围和所需承担的责任[6]。同时,要保证招投标审 查文件内容的可靠性和公正性, 对于有违反国家相关政策 的的条款要及时进行更改。从一般情况来看,招投标文件中 必须明确以下几点内容: 招标的目的、招标项目性质、招标 项目范围、工程建设技术要求、评标标准、附属条款等基本 内容, 这些内容必须按照行业规范和国家规定标准进行制 定,保证招投标文件的规范性,也是对各利益主体的基本保 障。而对于行政监督管理部门来讲,应做好招投标文件的审 核工作,在保证招投标文件质量的基础上,还要为招投标决 策的制定提供更多可以参考的文件或规定标准, 这样即使
出现问题,招投标单位也可以通过参考文件的内容,即使找 到出现问题的原因,方面对相关负责人的责任追究。

\section{4 规范招投标监督管理工作}

要想顺利进行招投标工作, 不仅需要对各个主要环节 和各个主体的行为进行规范, 还要制定强有力的监管制度 和措施, 以避免招投标活动中出现不公平、不公正现象。对 于招标单位来讲,招标活动中的所有环节, 都必须遵守公开、 公正、工平、透明的原则, 并在工程建设项目的特点和性质 基础上,合理的设定最高限价。在招标公告、制定招标问价、 资格审查以及评标环节中, 行政监督管理部门要进一步提 高监察力度, 对每个细节都进行严格的审查, 一旦发现存在 违规行为或制定内容不合理现象时,应及时的制止, 并纠正 不合理之处要求相关单位及时更改[7]。尽量恶意竞标和恶 意投标现象,维护招投标市场的稳定发展,为招投标活动创 造稳定、健康的发展环境。

\section{5 加大对违规行为的处罚力度}

对于招投标活动中存在的违法行为, 相关部门一定要 给予高度重视, 招投标活动中的违法行为不仅损害的了国 家的利益, 还威胁了人民利益和社会财产安全, 所以必须按 照我国《招标法》中的法律规定,对存在问题的个人或单位 进行严厉的惩处, 不得再对违规行为进行放纵, 如果出现这 样的行为要连同行政部门处理人员一同进行处罚。同时要 构建工程建设行业信誉数据库, 对每个工程公司的行为和 损害信誉的行为都要进行详细记录, 并上报到国家相关部 门报备,其中涉及情节严重的公司取消其招投标权利,并作 出相应的处分, 通过这样的方式对招投标市场进行严格的 管理,保证良好的秩序。

\section{3 结束语}

随着市场经济的发展和各项制度的完善, 招投标活动 的应用越来越频繁, 而且其中还存在不规范的违法行为,所 以相关部门一定要给予高度重视, 强化对招投标工作的管 理,为招投标市场创造一个公平、公正、公开的发展环境,从 而推动我国建筑行业的持续发展。

\section{参考文献:}

[1] 郭清涌,李清宝.招投标程序“三坚持”规范集体“三 资“管理[J].中国农业会计,2013,19(3):22-23.

[2]张峥栋.工程建设项目招投标程序管理研究 [J].住 宅与房地产,2017,21(3):41.

[3]李明珠, 万帮庆,冀风昌等. 工程建设项目招投标程 序管理 [J]. 城市建设理论研究（电子版),2016,25(14): 1615-1615.

[4] 沈靖红. 浅析工程项目招投标程序中的风险管控 [J].门窗,2016,32(12):45-46.

[5]朱中华. 关于中国建设工程强制招标制度的探讨 [J].招标采购管理,2015,(01):22-24. 